\title{
Experimental Investigation of Material Properties in FSW Dissimilar Aluminum-Steel Lap Joints
}

\author{
Michelangelo Mortello ${ }^{1, *}$, Matteo Pedemonte ${ }^{1}$, Nicola Contuzzi ${ }^{2}$ (D) and Giuseppe Casalino ${ }^{2}$ (D) \\ 1 Istituto Italiano della Saldatura, Lungobisagno Istria 15, 16141 Genova, Italy; matteo.pedemonte@iis.it \\ 2 Dipartimento di Meccanica, Matematica e Management, Polytechnic University of Bari, Via Orabona 4, \\ 70125 Bari, Italy; nicola.contuzzi@poliba.it (N.C.); giuseppe.casalino@poliba.it (G.C.) \\ * Correspondence: Michelangelo.mortello@iis.it; Tel.: +39-010-8341-539
}

Citation: Mortello, M.; Pedemonte,

M.; Contuzzi, N.; Casalino, G.

Experimental Investigation of

Material Properties in FSW Dissimilar

Aluminum-Steel Lap Joints. Metals

2021, 11, 1474. https://doi.org/

10.3390/met11091474

Academic Editors: Evgeny

A. Kolubaev and António

Bastos Pereira

Received: 13 July 2021

Accepted: 10 September 2021

Published: 16 September 2021

Publisher's Note: MDPI stays neutral with regard to jurisdictional claims in published maps and institutional affiliations.

Copyright: (c) 2021 by the authors. Licensee MDPI, Basel, Switzerland. This article is an open access article distributed under the terms and conditions of the Creative Commons Attribution (CC BY) license (https:// creativecommons.org/licenses/by/ $4.0 /)$.

\begin{abstract}
The friction stir lap welding of AA5083 H111 aluminum alloy and S355J2 grade DH36 structural steel was investigated. A polycrystalline cubic boron nitride with tungsten and rhenium additives tool was used. According to visual inspection, radiographic examination, and tensile test, it was observed that the best results were obtained for rotation speeds of about 700-800 rpm, with a feed speed ranging between 1.3 and $1.9 \mathrm{~mm} / \mathrm{s}$. From the fatigue tests, it is possible to state that there was a preferential propagation of cracks in the part of the aluminum alloy base material. Furthermore, a different response to fatigue stress for samples extracted from the same weld at different positions was observed, which introduces an overall variability in weld behavior along the welding direction. The specimens obtained in the second part of the weld endured a larger number of cycles before reaching failure, which can be related to progressively varying thermal conditions, dissipation behavior, and better metal coupling as the tool travels along the welding line.
\end{abstract}

Keywords: friction stir welding; mechanical properties; dissimilar aluminum-steel lap joints

\section{Introduction}

In recent years, aluminum has experienced a high demand from industries because of its outstanding properties, including high resistance-to-weight ratio, ductility, and high corrosion resistance, which allowed it to be exploited for shipbuilding, automotive applications, and aeronautics. Because of their high strength and lightweight properties, magnesium-based aluminum alloys enable the production of highly performing and extremely durable hulls, decks, and bulkheads. In particular, Aluminum 5083 is known for exceptional high-resistance performance in harsh environments, including seawater and industrial-chemical environments. It also retains exceptional strength after welding. Typical applications are shipbuilding, rail cars, vehicle bodies, tip truck bodies, mine skips, and cages and pressure vessels.

Despite the mentioned benefits and the large use for different assemblies, fusion welding of aluminum alloys is challenging since it can lead to metallurgical defects, mechanical discontinuities, and reductions in mechanical properties. Solid-state welding introduces the key advantage of avoiding the fusion and limiting thermal effect on material properties, leading to improved weld quality.

Within naval sector applications, the use of steel is also well recognized because of several advantages including weight reduction of about $40 \%$ compared with a similar wooden structure, simplicity of structuring, larger load capacity, larger impermeability of the planking and absence of caulking, higher durability, and ease of repair [1]. For example, S355J2 grade DH36 structural steel is used in the naval sector as a structural steel for the hull; it possesses good characteristics of toughness, machinability, and weldability, together with a good impact resistance (also at sub-zero temperatures).

Joining aluminum to steel enables the ability to design and fabricate components whose properties are customized to locally varying environmental conditions. However, 
dissimilar joining is highly affected by differences in thermal properties, limited mutual solubility, and metallurgical compatibility. These challenges have raised the importance of assessing the use of solid-state approaches, like Friction Stir Welding (FSW) for aluminumto steel assemblies.

Friction Stir Welding (FSW) was invented and patented in 1991 [2], and in the early stages of development companies have implemented the process predominantly in the fabrication of aluminum components and panels [3].

FSW processes for steels require improvements to tool material technology and process control. The process economy for steel welding has not been fully established; moreover, the robustness of the process for shipyard applications requires further consideration.

It is necessary to consider that the selection of the material to be adopted for the construction of the tool is limited due to the high temperatures reached during the process (about $1000-1200^{\circ} \mathrm{C}$ ). An essential requirement for successfully carrying out the welding is that the tool does not suffer degradation actions caused by wear, deformations, microstructural instability, fracture, or reactivity with the material that constitutes the workpiece. The tool is considered as the most critical component for performing a highly efficient defect-free joint [4]. During FSW of Al to steel, Zhou et al. [5] totally plunged the pin into the Al plate in order to avoid tool wear and this produced a diffusion layer at the interface, rather than an intermetallic layer with enhanced atomic migration. Refractory alloys based on the tungsten-rhenium system [6] are widely adopted for steel processing; they consist of a ceramic solution based on polycrystalline cubic boron nitride (PCBN) [7] and Co-based alloy with the $\gamma / \gamma^{\prime}$ microstructure strengthened by precipitating intermetallics, $\mathrm{Co}_{3}(\mathrm{Al}, \mathrm{W})$, with an $\mathrm{L}_{12}$ structure [8-13]. In particular, the wear of PCBN FSW tool was investigated experimentally and numerically by Almoussavi et al., who determined that the tool shoulder periphery and probe side bottom are the most vulnerable parts suffering from wear issues [14]. As confirmed by Soresen et al., PCBN tools provide high quality finish when used for FSW of both ferrous alloys [15].

The study of weld process parameters, dissimilar to the $\mathrm{Al} /$ steel joint, is of great importance as it determines the heat input [16-19]. Elrefaey et al. [20] welded a plate of commercially pure aluminum (AA $1100 \mathrm{H} 24$ ) to a plate of low-carbon steel (SPCC) in lap joint configuration and found that by increasing the rotation speed and decreasing the travel speed, grains of both aluminum and steel, in all characteristic areas, were coarsened and that a slight difference in pin depth $(0.1 \mathrm{~mm})$ has a significant effect on the performance of the lap joints. Kimapong and Watanabe [21] found that when welding A5083 aluminum alloy and a SS400 mild steel joint, it happens that increasing the tool rotational speed decreased the shear load of the joint because the higher rotational speed formed a thick $\mathrm{FeAl} 3$ intermetallic compound at the interface between aluminum and steel, and increasing the traverse speed of the tool increased the shear load of joints. Chen et al. [22] studied the effects of tool positioning on microstructures formed in the Al-to-steel interface region and reported that when the pin was close to the bottom steel piece, Al-to-steel reaction occurred, resulting in intermetallic outbursts formed along the interface, while when the pin approached the steel, a thin and continued interface intermetallic layer was formed. Wan et al. [23] enhanced the strength at the interface and eliminated the hook effect by adopting an enlarged pin head with circumferential notches.

In this paper, Friction Stir Welding between AA5083 H111 aluminum alloy and S355J2 grade DH36 structural steel dissimilar in lap joint configuration, with a polycrystalline cubic boron nitride with tungsten and rhenium additives tool, was presented. Sheets were welded under different conditions, FSW tool axial force, rotation speed, and welding speed. The quality of the FSW joint was evaluated by visual examination, X-ray tests (by ascertain the presence of macroscopic defects, such as incomplete welding penetration, cracks), and tensile and fatigue tests. 


\section{Materials and Methods}

\subsection{Materials}

The used materials were AA5083 H111 aluminum alloy and S355J2 grade DH36 structural steel. The chemical composition and the mechanical characteristics of both materials are shown in Tables 1 and 2.

Table 1. Average composition (weight \%).

\begin{tabular}{|c|c|c|c|c|c|c|c|c|c|c|c|c|}
\hline \multicolumn{13}{|c|}{ AA 5083 H111 } \\
\hline \multirow{3}{*}{\multicolumn{2}{|c|}{$\begin{array}{c}\mathrm{Mg} \\
4.0 \div 4.9\end{array}$}} & \multirow{3}{*}{\multicolumn{2}{|c|}{$\begin{array}{c}\mathrm{Si} \\
0.40\end{array}$}} & \multirow{2}{*}{\multicolumn{2}{|c|}{$\begin{array}{c}\mathrm{Fe} \\
0.40\end{array}$}} & \multirow{2}{*}{\multicolumn{2}{|c|}{$\begin{array}{l}\mathrm{Cu} \\
0.10\end{array}$}} & $\mathrm{Mn}$ & \multirow{2}{*}{\multicolumn{2}{|c|}{$\begin{array}{c}\mathrm{Cr} \\
0.05-0.25\end{array}$}} & \multirow{2}{*}{\multicolumn{2}{|c|}{$\begin{array}{c}\mathrm{Zn} \\
0.25\end{array}$}} \\
\hline & & & & & & & & $0.40-1.0$ & & & & \\
\hline & & & & & S355] & grade $\mathrm{D}$ & & & & & & \\
\hline $\mathrm{C} \max$ & Si max & $S$ max & Al & $\mathrm{Mn}$ & Cr max & Ni max & $\mathrm{P} \max$ & Ti max & Cu max & Mo max & $\mathrm{Nb}$ & V \\
\hline
\end{tabular}

Table 2. Mechanical property.

\begin{tabular}{ccc}
\hline & $\mathbf{5 0 8 3} \mathbf{H 1 1 1}$ & \\
\hline$R m(\mathrm{MPa})$ & $R p_{0.2}(\mathrm{MPa})$ & $A(\%)$ \\
275 & 125 & 16 \\
& S355J2 grade DH36 & $A(\%)$ \\
$R m(\mathrm{MPa})$ & $\operatorname{Re} \min (\mathrm{MPa})$ & 21 \\
$490 \div 630$ & 350 & 21 \\
\hline
\end{tabular}

\subsection{Methods}

$500 \times 200 \times 4 \mathrm{~mm}^{3}$ thick plates were used in lap joint configuration. The steel plate was $1.5 \mathrm{~mm}$ thick while the aluminum plate was $4 \mathrm{~mm}$ thick. The aluminum plate was machined in order to remove a surface skin depth and thus favor the overlap on the steel, as shown in Figure 1a. The schematic set-up is shown in Figure 1b.

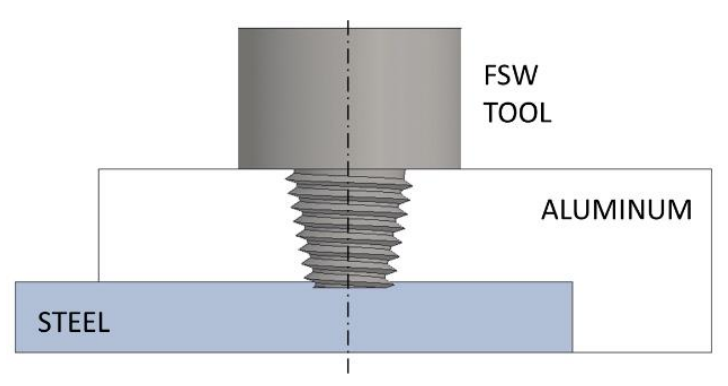

(a)

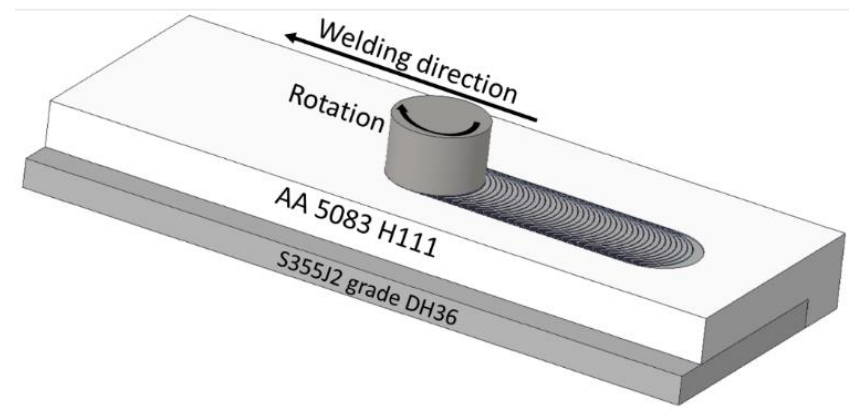

(b)

Figure 1. Schematic setup of the process in cross sectional (a) and axonometry (b) view.

Tests were carried out with a H. Loitz-Robotik (Hamburg, Germany) machine with a nominal torque of $70 \mathrm{Nm}$ up to $3050 \mathrm{rpm}$, a tilt angle range of $+/-3^{\circ}$, and a maximum vertical force of $60 \mathrm{kN}$ (Figure 2). In particular, the present paper focuses on specimens produced with $1^{\circ}$ tilt angle. 


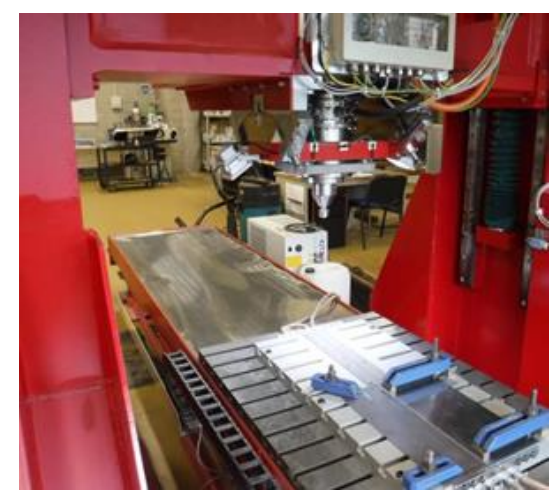

Figure 2. H. Loitz-Robotik Machine set up.

The tool (Figure 3), produced by MegaStir (Provo, UR, USA), with the abbreviation Q70 (70\% PCBN, 30\% WRe), was made of polycrystalline cubic boron nitride (PCBN) with tungsten and rhenium additives (WRe), which guarantee high thermal and mechanical properties to cope with wear problems. In addition, the tool has a micro hardness of 2600-3500 HV and a low coefficient of friction which affects the final roughness of the joint, improving the appearance [15].

Tool pin length was equal to $4.78 \mathrm{~mm}$ and shoulder diameter was equal to $36.8 \mathrm{~mm}$. A profilometer was used to monitor the tool wear state (Figure 3).

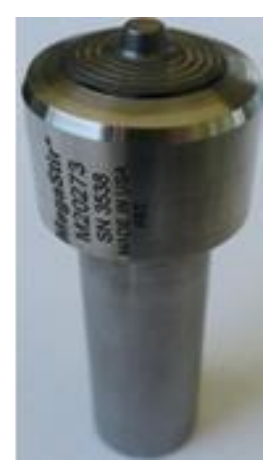

Figure 3. Megastir Q70 (PCBN/WRe) tool.

Joints were made by using axial force control, where the tool penetration depth varies to keep the applied tool force constant. In addition, for each weld, a set of process parameters, which include axial force, rotational speed $(\omega)$, and welding speed $(v)$, was identified (Table 3). For all trials selected, a tool tilt angle of $1^{\circ}$ was adopted. Since a specific set of specimens was selected from an original batch of more than thousand trials, the numbering was kept as the original one and only the specimens assessed in the present investigation were considered.

To verify the presence of defects in the specimens, X-ray examination was carried out. Characterization of mechanical properties was carried out by testing lap shear specimens in the transverse direction, $25 \mathrm{~mm}$ width, using a Zwick (Ulm, Germany) Z600 machine with a $600 \mathrm{kN}$ load cell at $2 \mathrm{~mm} / \mathrm{min}$ at room temperature. The fatigue tests were performed on the same specimen geometry used for testing the static properties, with a Zwick (Ulm, Germany) Vibrophore 250 machine. 
Table 3. Process parameters.

\begin{tabular}{ccccc}
\hline $\begin{array}{c}\text { Samples } \\
\text { (Original Batch) }\end{array}$ & Force (kN) & $\begin{array}{c}\text { Travel Speed } \\
(\mathbf{m m} / \mathbf{s})\end{array}$ & $\begin{array}{c}\text { Rotational } \\
\text { Speed (rpm) }\end{array}$ & $\begin{array}{c}\text { Weld Length } \\
\mathbf{( m m})\end{array}$ \\
\hline 953 & 20.75 & 1.3 & 800 & 230 \\
954 & 21.25 & 1.3 & 800 & 230 \\
957 & 21 & 1.7 & 800 & 230 \\
958 & 21 & 1.7 & 1000 & 230 \\
959 & 21 & 1.7 & 800 & 430 \\
987 & 21 & 1.2 & 1000 & 430 \\
988 & 21 & 1.9 & 900 & 430 \\
990 & 21 & 2.1 & 700 & 430 \\
992 & 21 & 1.2 & 900 & 430 \\
993 & 24.5 & 1.2 & 1000 & 430 \\
994 & 28.5 & 1.5 & 700 & 430 \\
998 & 24.5 & 1.5 & 800 & 160 \\
995 & 26.3 & 1.7 & 700 & 430 \\
984 & 21 & 1.7 & 800 & 430 \\
985 & 21 & 1.7 & 800 & 430 \\
999 & 21 & 1.7 & 800 & 150 \\
996 & 30 & 1.9 & 700 & 275 \\
997 & 26.3 & 1.9 & 700 & 150 \\
1000 & 27 & 1.9 & 800 & 145 \\
\hline
\end{tabular}

\section{Results}

Figures 4-6 show the top view of welds 994, 995, and 999, respectively. All welds presented a regular bead or reduced flash and a slightly rough surface. Despite that the process parameters adopted were different, a similar quality of beads can be explained considering that the combinations of parameters selected lay within the weldability window. Sample 994 was produced with a significantly larger force compared with sample 999, but the lower rotational speed led to less energy input to foster the plasticization. This is due to the tool material, since the polycrystalline cubic boron nitride tools produces smooth surfaces on the weld due to the low coefficient of friction between PCBN and metals [15]. Figure 7 shows a detail of the macro- and micro-section of sample 987.

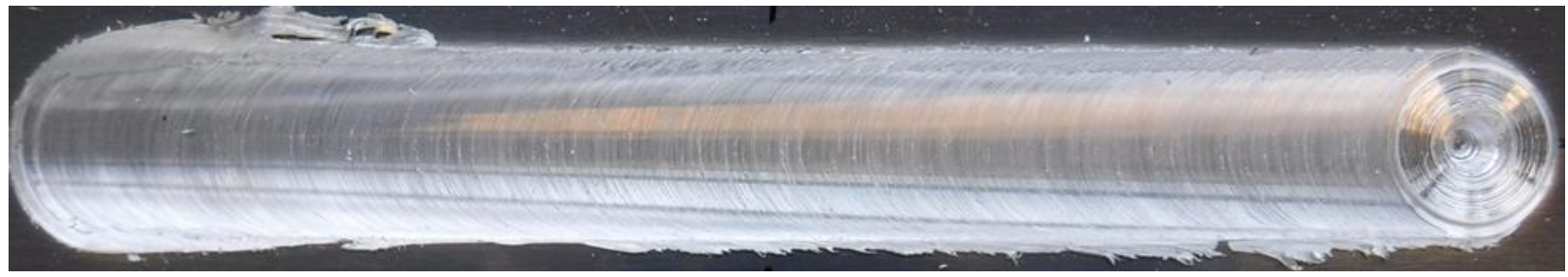

Figure 4. Sample 994.

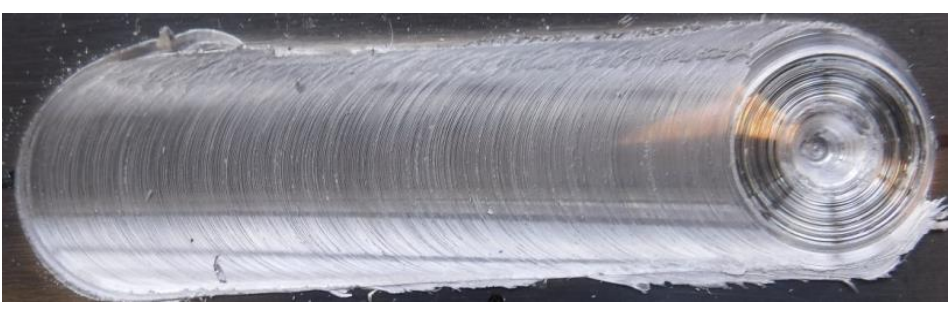

Figure 5. Sample 995. 


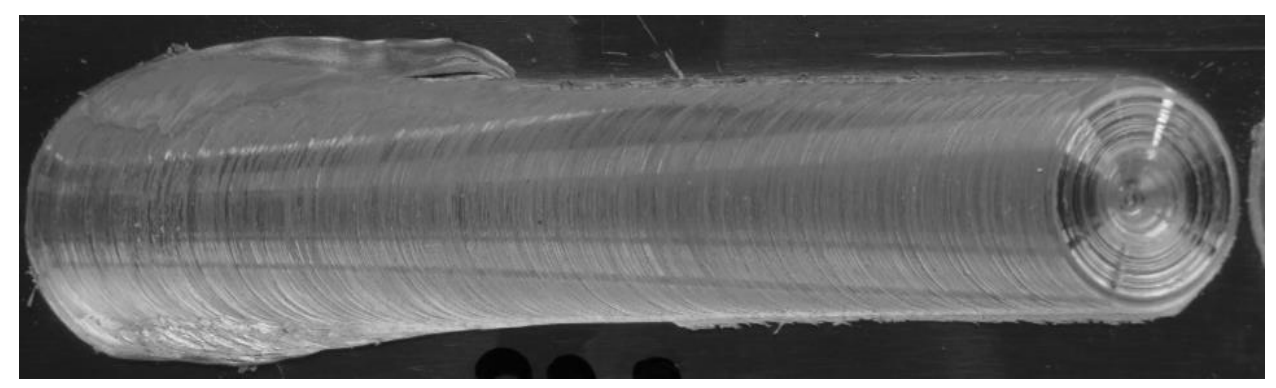

Figure 6. Sample 999.

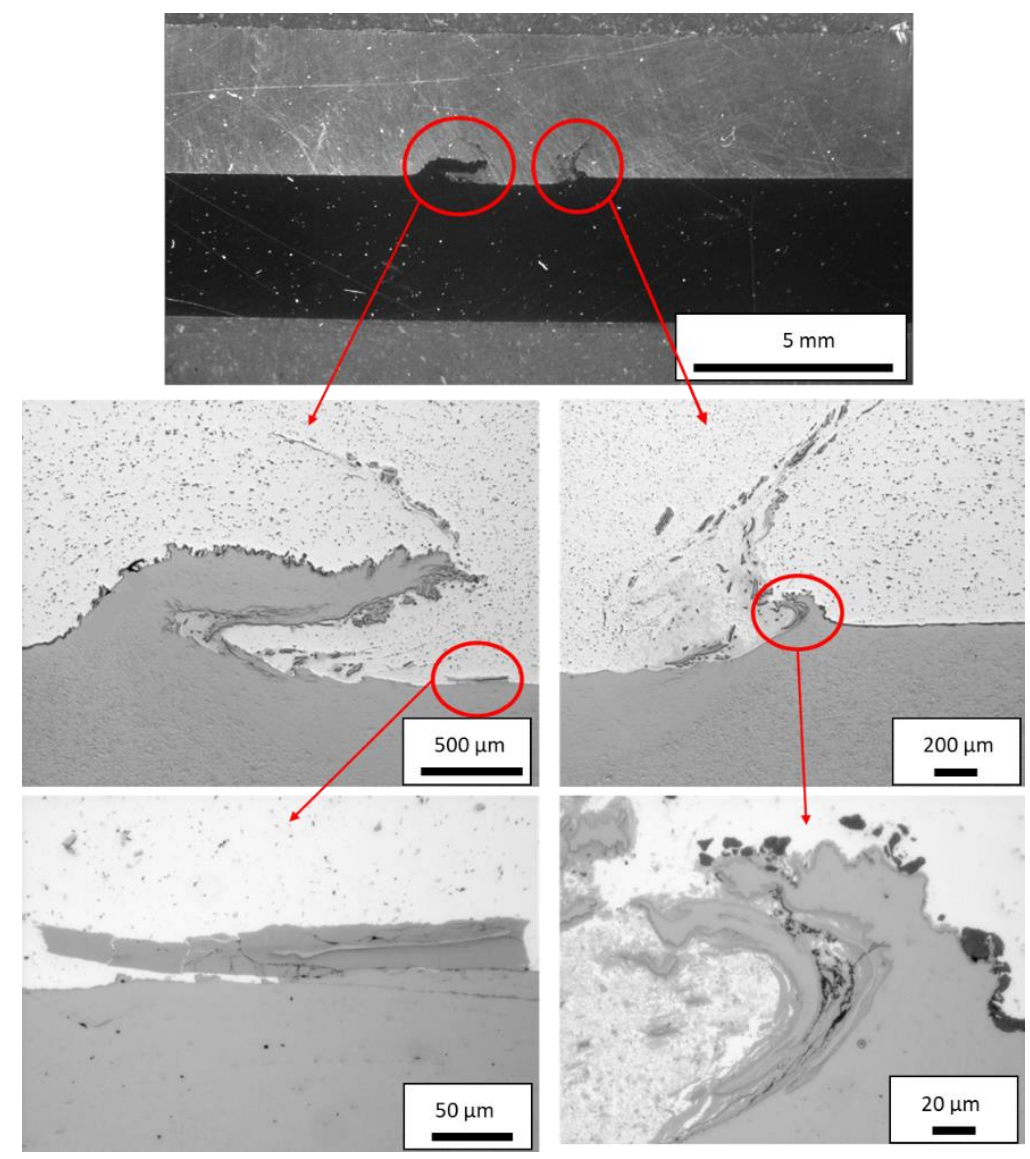

Figure 7. Sample 987 macro- and micro-section.

The picture shows the joint metallurgy within the stir zone (SZ), where refined and equiaxed grains were found because of the dynamic recrystallization linked to plastic deformation and heat input.

It is possible to observe the interconnection at the interface between $\mathrm{Al}$ and steel where the latter penetrates into the aluminum matrix due to the stirring effect performed by the pin. At the same time, a thin intermetallic layer at the interface between aluminum and steel was formed. It is possible to observe the action area of the pin and the characteristic hook shape generated by the roto-translational movement of the tool. In fact, in the interface area, the mechanical anchoring that the steel generated in the aluminum plate following plasticization and dynamic recrystallization is highlighted; the combination of mechanical anchoring together with diffusive phenomena between aluminum and steel are the two factors on which the mechanical strength that characterizes the joint directly depends.

Although the chemistry analysis is not in the scope of the present research, results reported in the literature for similar morphologies revealed the presence of intermetallics 
compounds whose compositions vary in stoichiometry [24]. In fact, the heat input and high strain rate deformation lead to diffusion-based formation of the $\mathrm{Fe}_{\mathrm{x}} \mathrm{Al}_{\mathrm{y}}$ intermetallic layer and the thickness and morphology of such layer is highly dependent on process parameters and consequent thermal history. In Figure 7, it can be observed that the intermetallics appearance is not homogenous along the interface. Since the steel protruded towards the Al side, the variation in stirring effect and local gradients in the thermal cycles generated gradients in intermetallics composition, as demonstrated by the different morphology.

Figure 7 also presents some voids at the interface, which can be related to slightly high process speed. In fact, in this case, the cooling rate was slower and it happens that in the stir-processed zone after welding, an excessive release of stirred materials to the upper surface resulted in voids formation.

X-ray tests were performed to check for defects in the joints. In most of the joints, no defects were identified (Figures 8a and 9).

(a)

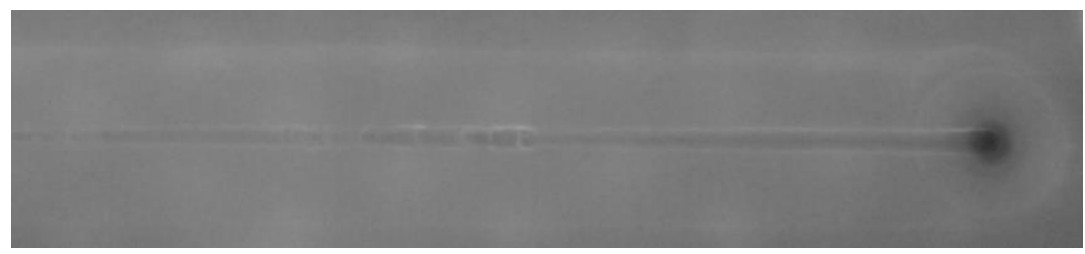

(b)

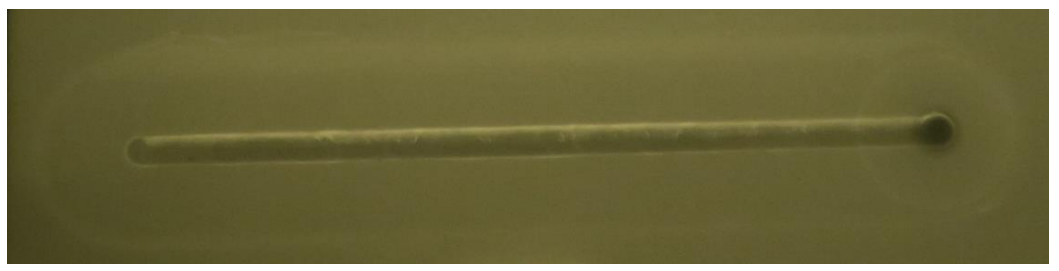

Figure 8. X-ray test for samples 953 (a) and 996 (b).

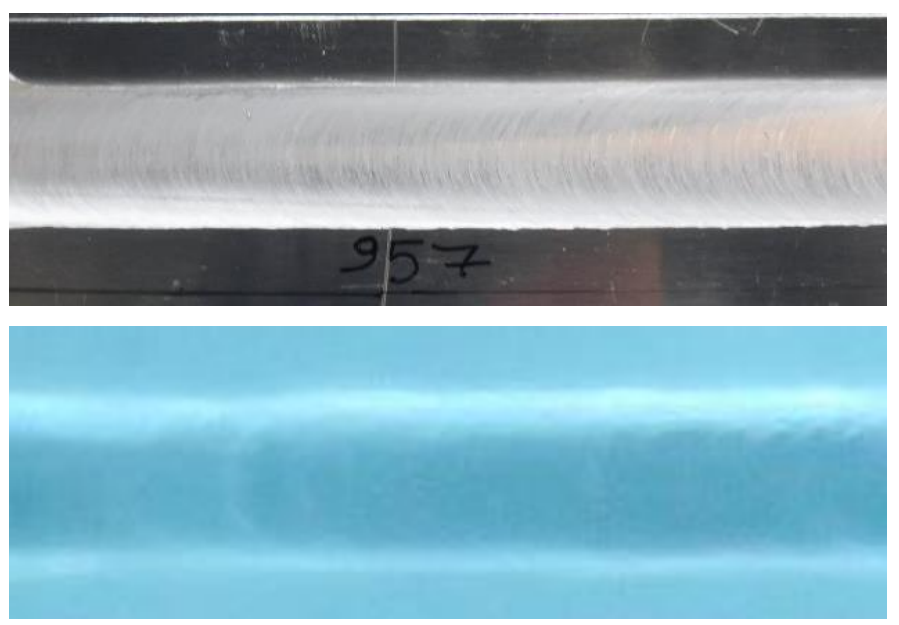

Figure 9. X-ray test for sample 957.

Specimens were extracted from the welds for the tensile and fatigue tests. As shown in Figure 10, the samples were indicated with letters, where A indicates the specimen taken in the initial part of the joint and consecutive letters indicate progressively closer positions towards the final part of the bead.

Table 4 shows the results obtained by the shear test. Analyzing the results, it is observed that as the welding speed varied, the best resistance values were obtained for reduced rotation speeds, until about of 700-800 rpm. 


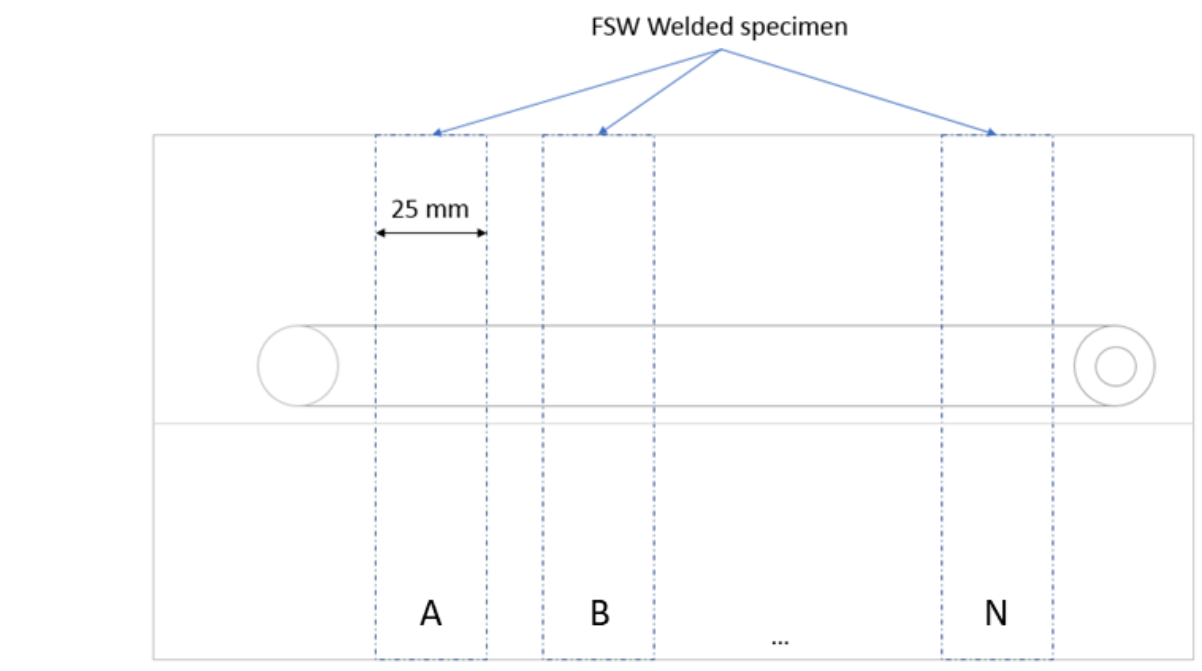

FSW Welded samples

Figure 10. Tensile and fatigue tests samples.

Table 4. Shear test results.

\begin{tabular}{|c|c|c|}
\hline $\mathbf{N}^{\circ}$ & Position & $F_{\max }(\mathrm{kN})$ \\
\hline \multirow{2}{*}{954} & A & 7 \\
\hline & B & 9 \\
\hline \multirow{2}{*}{957} & A & 13 \\
\hline & B & 15 \\
\hline \multirow{2}{*}{958} & A & 12 \\
\hline & B & 13 \\
\hline \multirow{2}{*}{959} & A & 12 \\
\hline & B & 15 \\
\hline \multirow{11}{*}{994} & A & 13 \\
\hline & B & 10 \\
\hline & $C$ & 12 \\
\hline & $\mathrm{D}$ & 9 \\
\hline & $\mathrm{E}$ & 7 \\
\hline & $\mathrm{F}$ & 12 \\
\hline & $\mathrm{G}$ & 15 \\
\hline & $\mathrm{H}$ & 4 \\
\hline & I & 5 \\
\hline & $\mathrm{J}$ & 12 \\
\hline & $\mathrm{K}$ & 11 \\
\hline \multirow{2}{*}{996} & A & 16 \\
\hline & B & 16 \\
\hline \multirow{3}{*}{998} & A & 10 \\
\hline & B & 16 \\
\hline & $\mathrm{C}$ & 15 \\
\hline \multirow{3}{*}{999} & A & 5 \\
\hline & B & 11 \\
\hline & $\mathrm{C}$ & 10 \\
\hline
\end{tabular}


The highest tensile strength values were obtained for a thickness of $1.5 \mu \mathrm{m}$, while a decreasing trend was found for lower or higher values.

Scanning electron microscopy (SEM) analyses were conducted on specimens 987, 988, 990, and 992 and a measurement of IMC at its peak thickness was conducted. Measurements made it possible to identify the intermetallics present, $\mathrm{FeAl}_{3}$ and $\mathrm{FeAl}_{6}$, and to evaluate their relative thickness. Figure 11 shows the trend of the force as a function of the thickness of the intermetallic for some of the specimens, in order to show how the increase in IMCS within the range 1.5 to $2.1 \mu \mathrm{m}$ thickness resulted in a decrease of shear strength. This aspect has brought out how much, in addition to brittleness, the structure can be compromised in terms of maximum resistance as the formation of intermetallic compounds increases, especially beyond certain threshold values.

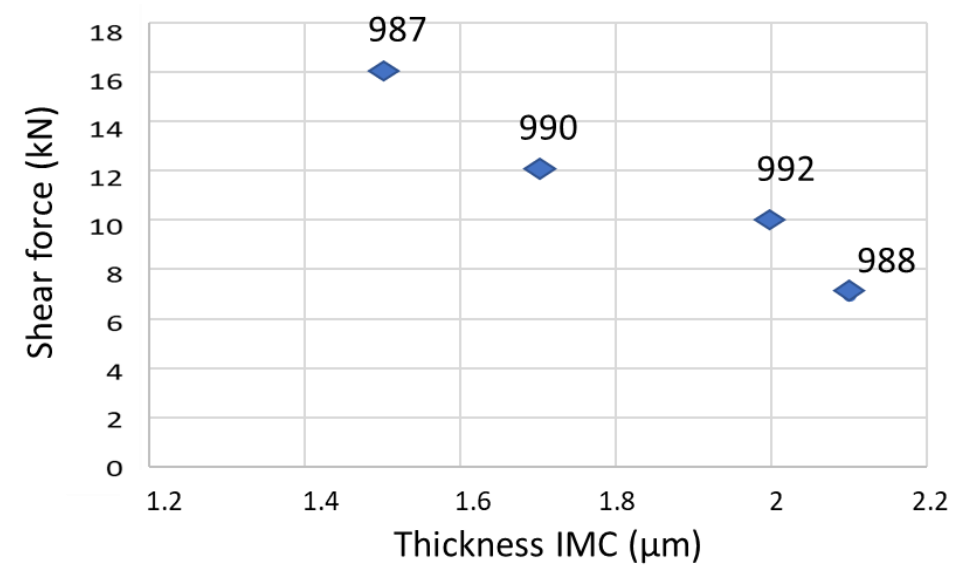

Figure 11. Shear force versus intermetallic thickness.

The fatigue test was performed on specimens 957 and 996 . Figure 12 shows the fracture zone for specimen 957 . The fatigue test was performed on five samples obtained from specimen 957 and eleven samples from specimen 996 and the test results are reported in Tables 5 and 6 and in Figures 13 and 14.

(a)

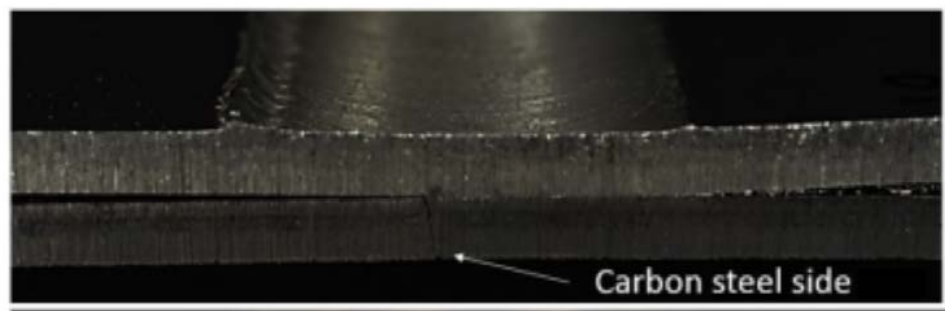

(b)

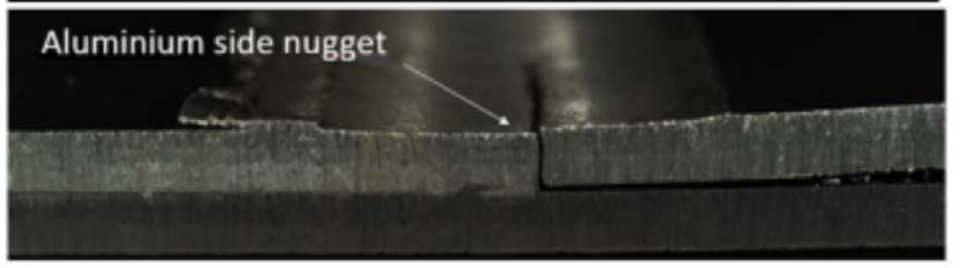

Figure 12. Fracture zone for welding 957 specimen (a) and welding 3 specimen (b).

Table 5. Fatigue test process parameters and results on sample 3.

\begin{tabular}{ccccccccc}
\hline Samples & $\begin{array}{c}\sigma_{\max } \\
\mathbf{( N )}\end{array}$ & $\begin{array}{c}\sigma_{\min } \\
\mathbf{( N )}\end{array}$ & $\begin{array}{c}\sigma_{\mathbf{m}} \\
\mathbf{( N )}\end{array}$ & $\begin{array}{c}\Delta \boldsymbol{\sigma} / \mathbf{2} \\
\mathbf{( N )}\end{array}$ & $\begin{array}{c}\boldsymbol{\Delta} \boldsymbol{\sigma} \\
\mathbf{( N )}\end{array}$ & $\boldsymbol{R}$ & $\begin{array}{c}\text { Number of Cycles } \\
\text { at Break }\end{array}$ & Fracture Zone \\
\hline A & 7750 & 1250 & 4500 & 3250 & 6500 & 0.16 & $2,084,900$ & TMAZ steel \\
B & 8500 & 500 & 4500 & 4000 & 8000 & 0.06 & 49,814 & nugget \\
C & 7750 & 1250 & 4500 & 3250 & 6500 & 0.16 & $3,551,460$ & TMAZ steel \\
D & 8500 & 500 & 4500 & 4000 & 8000 & 0.06 & 395,000 & nugget \\
G & 8500 & 500 & 4500 & 4000 & 8000 & 0.06 & 229,670 & nugget \\
\hline
\end{tabular}


Table 6. Fatigue test process parameters and results on sample 9.

\begin{tabular}{ccccccccc}
\hline Samples & $\begin{array}{c}\sigma_{\max } \\
(\mathbf{N})\end{array}$ & $\begin{array}{c}\sigma_{\min } \\
\mathbf{( N )}\end{array}$ & $\begin{array}{c}\sigma_{\mathrm{m}} \\
(\mathbf{N})\end{array}$ & $\begin{array}{c}\boldsymbol{\Delta} \boldsymbol{\sigma / 2} \\
\mathbf{( N )}\end{array}$ & $\begin{array}{c}\boldsymbol{\Delta} \boldsymbol{\sigma} \\
\mathbf{( N )}\end{array}$ & $\boldsymbol{R}$ & $\begin{array}{c}\text { Number of Cycles } \\
\text { at Break }\end{array}$ & Fracture Zone \\
\hline $\mathrm{C}$ & 7750 & 1250 & 4500 & 3250 & 6500 & 0.16 & 339,710 & TMAZ aluminum \\
$\mathrm{D}$ & 7750 & 1250 & 4500 & 3250 & 6500 & 0.16 & 340,085 & TMAZ aluminum \\
E & 7750 & 1250 & 4500 & 3250 & 6500 & 0.16 & 330,360 & nugget \\
F & 8250 & 750 & 4500 & 3750 & 7500 & 0.09 & 136,590 & nugget \\
G & 7000 & 2000 & 4500 & 2500 & 5000 & 0.29 & $9,770,460$ & TMAZ aluminum \\
H & 7750 & 1250 & 4500 & 3250 & 6500 & 0.16 & $1,451,030$ & TMAZ aluminum \\
I & 8000 & 1000 & 4500 & 3500 & 7000 & 0.13 & 842,780 & TMAZ aluminum \\
L & 8500 & 500 & 4500 & 4000 & 8000 & 0.06 & 337,525 & nugget \\
M & 7500 & 1500 & 4500 & 3000 & 6000 & 0.20 & $1,535,770$ & TMAZ steel \\
N & 7750 & 1250 & 4500 & 3250 & 6500 & 0.16 & 263,130 & nugget \\
O & 8250 & 750 & 4500 & 3750 & 7500 & 0.09 & 531,589 & nugget \\
\hline
\end{tabular}

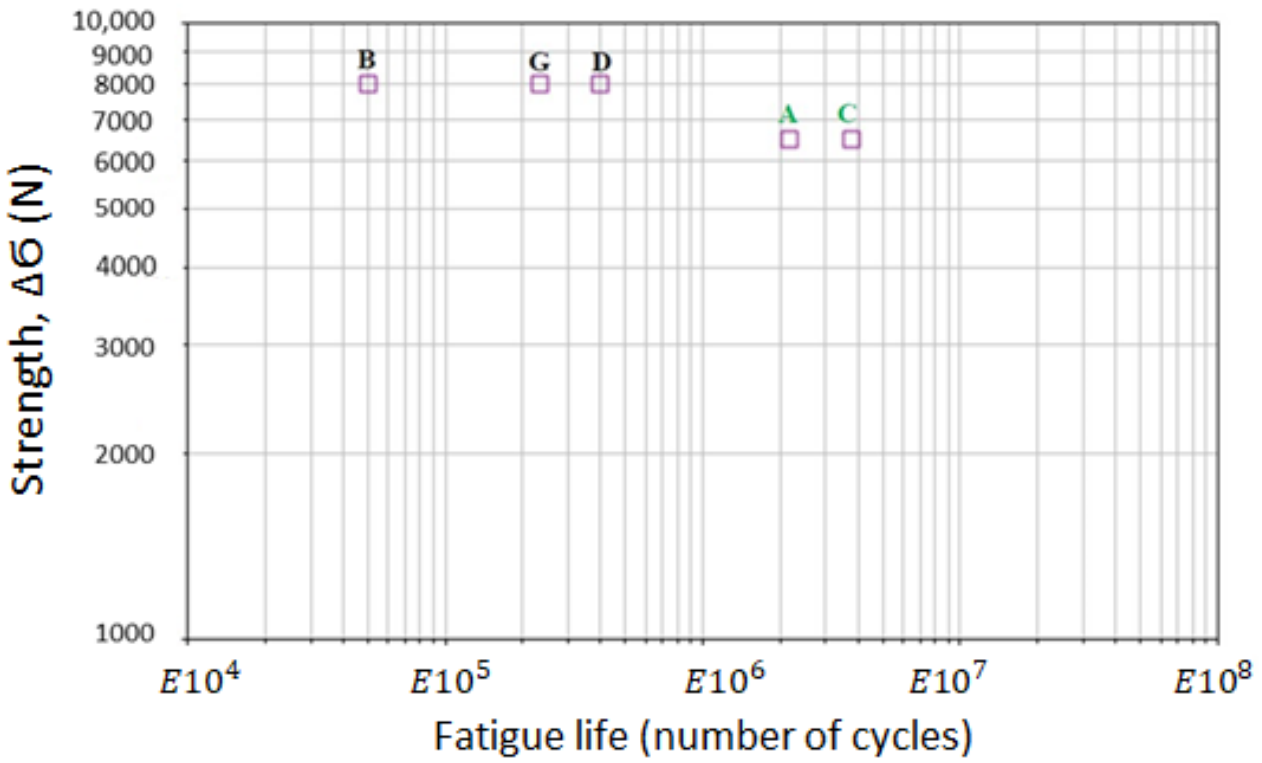

Figure 13. Number of cycles at break for sample 957.

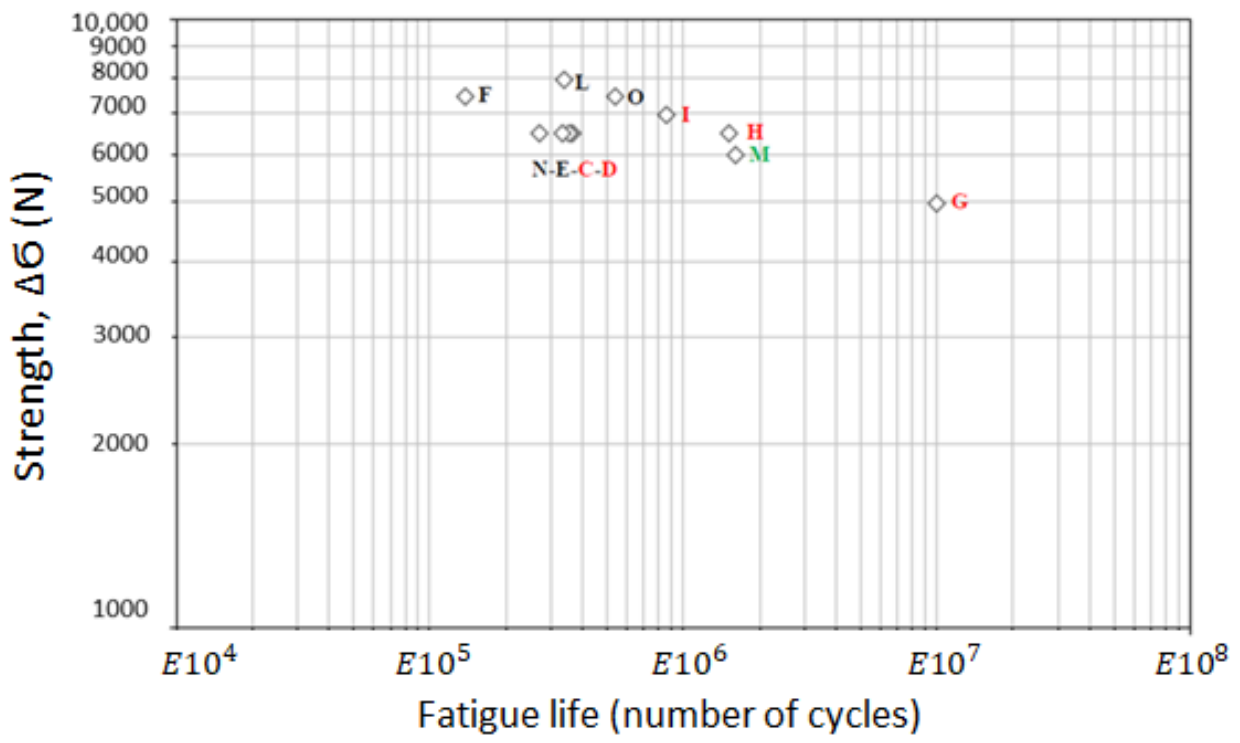

Figure 14. Number of cycles at break for sample 996.

Samples that reached the highest fatigue life values reported failure due to a crack originating in the base material; this indicates a good resistance of the joint. 
According to the analysis carried out on the specimens' fracture surfaces, there was a preferential propagation of the beginning of the break in the part of the base material in aluminum alloy.

This behavior could be linked to the greater stiffness that characterizes steel, which would "unload" the cyclic stresses of the fatigue test on the more deformable aluminum alloy.

Figure 15 shows a fracture that occurred near the HAZ on the aluminum side.

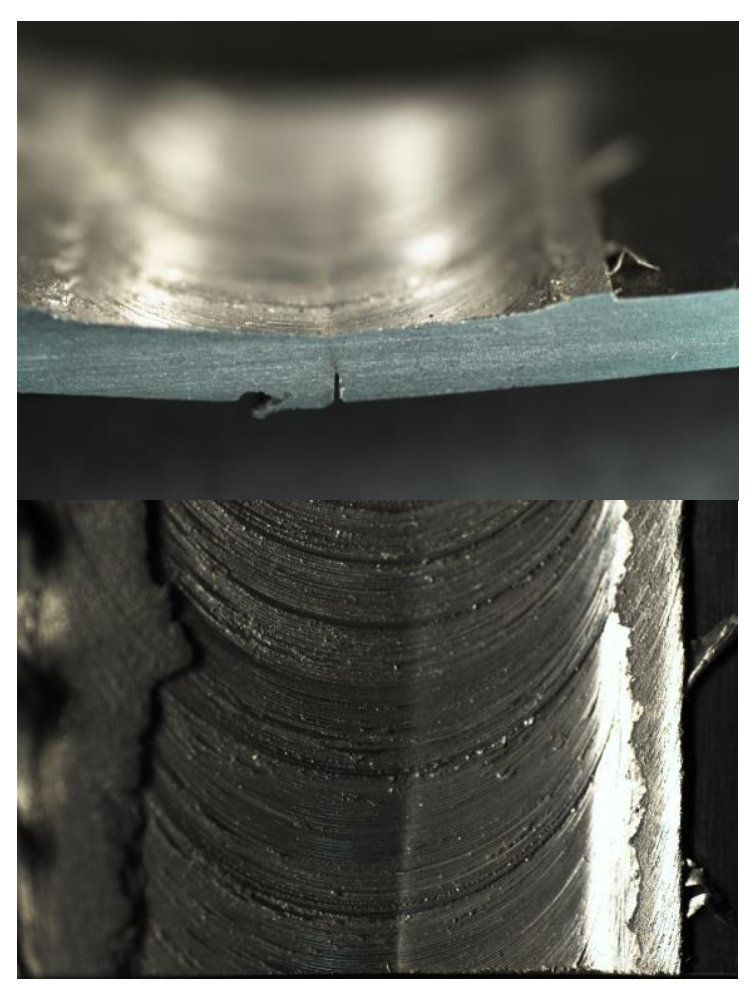

Figure 15. Fracture in the HAZ on the aluminum side for welding 9 specimen $\mathrm{C}$.

Although the fatigue samples were obtained from the same joint, they highlighted a different response to the fatigue stress; the specimens obtained in the second part of the weld endured a larger number of cycles before reaching failure.

At the beginning of the welding process, the materials were still cold and the aluminum dissipated more heat, leading to more severe thermal cycles and producing more fragile metal phases. Furthermore, the contact zone between aluminum and steel did not reach an optimal welding temperature, causing less efficient mixing of the materials.

As the process progressed, the temperature stabilized at the optimal one and the mixing action between the two metals improved, generating a more performing joint.

The fact that specimens obtained in the second part of the weld endured a larger number of cycles before reaching failure can also be related to progressively varying thermal conditions and tightening effect of bonding as the tool travels along the welding line.

\section{Conclusions}

In the current study, 4 mm-thick plate of AA5083 H111 aluminum alloy and S355J2 grade DH36 structural steel were lap-welded with by friction stir welding under different axial forces, travel speeds, and rotational speeds. A polycrystalline cubic boron nitride with tungsten and rhenium additives tool was used.

Combining visual and radiographic examination and tensile tests highlighted that the best results were obtained for rotation speeds of about 700-800 rpm with feed speeds between 1.3 and $2.1 \mathrm{~mm} / \mathrm{s}$. The weldability window can be circumscribed within the just mentioned ranges. Sample 996 presented the best results in terms of geometric defectiveness, shear resistance, and fatigue. 
As concerns fatigue tests, it is possible to state that, according to the analysis carried out with the scanning electron microscope on the fracture surfaces of the specimens, there is a preferential propagation of cracks in the aluminum alloy base material.

Furthermore, there was a different response to fatigue stress for samples obtained, in different positions, from the same weld. The specimens obtained in the second part of the weld endured a larger number of cycles before reaching failure. This can be related to variations in heat dissipation behavior and variations in material coupling in the contact zone. Mitigation actions could include thermal pre-treatment or customized tool paths, which in both cases would affect and stabilize the thermal history.

Author Contributions: Conceptualization, M.P.; methodology, M.P.; investigation, M.P.; writingoriginal draft preparation, N.C.; writing-review and editing, G.C.; visualization, M.P.; supervision, M.M.; project administration, M.P.; funding acquisition, M.P. All authors have read and agreed to the published version of the manuscript.

Funding: This research was funded by Regione Liguria, in the framework of POR FESR (2014-2020) Azione 1.2.4.

Data Availability Statement: Data presented in this article are available at request from the corresponding author.

Acknowledgments: The authors want to thank the CNR-ISMAC group for having given support in the execution of the experimental tests during the HybridJoin project.

Conflicts of Interest: The authors declare no conflict of interest.

\section{References}

1. Bertram, M.; Buxmann, K.; Furrer, P. Analysis of greenhouse gas emissions related to aluminum transport applications. Int. J. Life Cycle Assess. 2009, 14, S62-S69. [CrossRef]

2. Thomas, M.W.; Nicholas, E.D.; Needham, J.C.; Murch, M.G.; Temple-Smith, P.; Dawes, C.J. Friction Stir Butt Welding. International Patent No. 9,125,978.8, 6 December 1991.

3. Kallee, S.W. Industrial applications of friction stir welding. In Friction Stir Welding From Basics to Applications; Woodhead Publishing: Sawston, UK, 2010; pp. 118-163.

4. Casalino, G.; Campanelli, S.; Mortello, M. Influence of Shoulder Geometry and Coating of the Tool on the Friction Stir Welding of Aluminium Alloy Plates. Procedia Eng. 2014, 69, 1541-1548. [CrossRef]

5. Zhou, L.; Yu, M.; Liu, B.; Zhang, Z.; Liu, S.; Song, X.; Zhao, H. Microstructure and mechanical properties of Al/steel dissimilar welds fabricated by friction surfacing assisted friction stir lap welding. J. Mater. Res. Technol. 2019, 9, 212-221. [CrossRef]

6. Leonhardt, T.; Johnson, R. Processing and Properties of Tungsten Rhenium for Friction Stir Welding Application. In Proceedings of the Aeromat 20 Conference and Exposition American Society for Metals, Dayton, OH, USA, 7-11 June 2009.

7. Sorensen, C.D.; Nelson, T.W. Progress in Polycrystalline Cubic Boron Nitride Friction Stir Welding Process. In Proceedings of the 4th International Friction Stir Welding Symposium, Park City, UT, USA, 14-16 May 2003.

8. Sato, Y.S.; Miyake, M.; Imano, S.; Kokawa, H.; Omori, T.; Ishida, K.; Park, S.H.C.; Hirano, S. Development of a cobalt-based alloy fsw tool for high-softening-temperature materials. In Friction Stir Welding and Processing VI; Rajiv, S., Mishra, M.W., Yutaka, S., Yuri, H., Ravi, V., Eds.; Wiley: Hoboken, NJ, USA, 2011.

9. Sato, Y.S.; Miyake, M.; Susukida, S.; Kokawa, H.; Omori, T.; Ishida, K.; Imano, S.; Park, S.H.C.; Sugimoto, I.; Hirano, S. Performance Enhancement of Co-Based Alloy Tool for Friction Stir Welding of Ferritic Steel. In Friction Stir Welding and Processing VIII; Springer: Cham, Switzerland, 2015; pp. 39-46. [CrossRef]

10. Kumar, R.; Elango, V.; Giridharan, K.; Jothiprakash, V.; Stalin, B. Optimization and enhancement of friction stir welding strength on high yield strength deformed steel. Mater. Today Proc. 2020, 45, 1904-1907. [CrossRef]

11. Hovanski, Y.; Santella, M.; Grant, G. Friction stir spot welding of hot-stamped boron steel. Scr. Mater. 2007, 57, 873-876. [CrossRef]

12. Meinhardt, C.P.; Scheid, A.; Santos, J.F.d.; Bergmann, L.A.; Favaro, M.B.; Kwietniewski, C.E.F. Hydrogen embrittle-ment under cathodic protection of friction stir welded UNS S32760 super duplex stainless steel. Mater. Sci. Eng. A 2017, 706, 48-56. [CrossRef]

13. Giorjão, R.A.R.; Pereira, V.F.; Terada, M.; da Fonseca, E.B.; Marinho, R.R.; Garcia, D.M.; Tschiptschin, A.P. Microstructure and mechanical properties of friction stir welded $8 \mathrm{~mm}$ pipe SAF 2507 super duplex stainless steel. J. Mater. Res. Technol. 2019, 8, 243-249. [CrossRef]

14. Almoussawi, M.; Smith, A.J. Thermo-Mechanical Effect on Poly Crystalline Boron Nitride Tool Life during Friction Stir Welding (Dwell Period). Met. Mater. Int. 2018, 24, 560-575. [CrossRef]

15. Sorensen, C.D.; Nelson, T.W. Friction stir welding of ferrous and nickel alloys. In Friction Stir Welding and Processing; Mishra, R.S., Mahoney, M.W., Eds.; ASM International: Materials Park, OH, USA, 2007; Volume 6, pp. 111-121. 
16. Dehghani, M.; Amadeh, A.; Mousavi, S.A.A.A. Investigations on the effects of friction stir welding parameters on intermetallic and defect formation in joining aluminum alloy to mild steel. Mater. Des. 2013, 49, 433-441. [CrossRef]

17. Casalino, G.; Leo, P.; Mortello, M.; Perulli, P.; Varone, A. Effects of laser offset and hybrid welding on microstructure and IMC in $\mathrm{Fe}-\mathrm{Al}$ dissimilar welding. Metals 2017, 7, 282. [CrossRef]

18. Zhao, S.; Ni, J.; Wang, G.; Wang, Y.; Bi, Q.; Zhao, Y.; Liu, X. Effects of tool geometry on friction stir welding of AA6061 to TRIP steel. J. Mater. Process. Technol. 2018, 261, 39-49. [CrossRef]

19. Forcellese, A.; Simoncini, M.; Casalino, G. Influence of process parameters on the vertical forces generated during friction stir welding of AA6082-T6 and on the mechanical properties of the joints. Metals 2017, 7, 350. [CrossRef]

20. Elrefaey, A.; Gouda, M.; Takahashi, M.; Ikeuchi, K. Characterization of Aluminum/Steel Lap Joint by Friction Stir Welding. J. Mater. Eng. Perform. 2005, 14, 10-17. [CrossRef]

21. Kimapong, K.; Watanabe, T. Lap Joint of A5083 Aluminum Alloy and SS400 Steel by Friction Stir Welding. Mater. Trans. 2005, 46, 835-841. [CrossRef]

22. Chen, Z.W.; Yazdanian, S.; Littlefair, G. Effects of tool positioning on joint interface microstructure and fracture strength of friction stir lap Al-to-steel welds. J. Mater. Sci. 2013, 48, 2624-2634. [CrossRef]

23. Huang, Y.; Wan, L.; Huang, T.; Meng, X.; Xie, Y. Achieving high-quality Al/steel joint with ultrastrong interface. Metall. Mater. Trans. A 2019, 50, 295-299. [CrossRef]

24. Wang, T.; Sidhar, H.; Mishra, R.S.; Hovanski, Y.; Upadhyay, P.; Carlson, B. Evaluation of inter-metallic compound layer at aluminum/steel interface joined by friction stir scribe technology. Mater. Des. 2019, 174, 107795. [CrossRef] 